\title{
Theoretical Calculation and Simulation Analysis of Axial Static Stiffness of Double-Nut Ball Screw with Heavy Load and High Precision
}

\author{
Haitao Luo $\mathbb{D}^{1,2}$ Jia Fu, ${ }^{1,2}$ Lichuang Jiao, ${ }^{1,2}$ and Fengqun $\mathrm{Zhao}^{3}$ \\ ${ }^{1}$ State Key Laboratory of Robotics, Shenyang Institute of Automation, Chinese Academy of Sciences (CAS), Shenyang, China \\ ${ }^{2}$ Institute for Robotics and Intelligent Manufacturing, Chinese Academy of Sciences (CAS), Shenyang, China \\ ${ }^{3}$ School of Mechanical Engineering, Shenyang Ligong University, Shenyang, China \\ Correspondence should be addressed to Haitao Luo; luohaitao@sia.cn
}

Received 24 December 2018; Revised 2 June 2019; Accepted 11 June 2019; Published 27 June 2019

Academic Editor: Jixiang Yang

Copyright (C) 2019 Haitao Luo et al. This is an open access article distributed under the Creative Commons Attribution License, which permits unrestricted use, distribution, and reproduction in any medium, provided the original work is properly cited.

\begin{abstract}
Double-nut ball screws bear the action of bidirectional pretightening force, leading to the deformation of the contact area between the ball and the raceway. Under this condition, it is important to analyze and calculate the static stiffness of the ball screw. However, the conventional calculation method is inaccurate. Hence, a new method for the static stiffness analysis of a double-nut ball screw is proposed. Through the structural analysis of the ball screw and internal load distribution, a load deformation model was established based on the Hertzian contact theory. Through the load analysis of the ball screw, a static stiffness model of the ball screw was established and applied to a case study and a finite element simulation. The rigidity of THK double-nut ball screws used in the $\mathrm{X}$-axis feed system of a high-stiffness heavy-duty friction stir welding robot (developed by the research group) was calculated. When the workload was lower than $1.1 \times 10^{4} \mathrm{~N}$, the slope of the double-nut static stiffness curve increased significantly with the increase in the workload, and when the workload was greater than $1.1 \times 10^{4} \mathrm{~N}$, its upward slope tended to stabilize. The simulated and experimental stiffness curves were in good agreement; when the external axial load was greater than $2.8 \times 10^{4} \mathrm{~N}$, the stiffness value calculated using the finite element method gradually converged to the theoretical value; and when the axial load reached 3.0 $\times 10^{4} \mathrm{~N}$, the simulation and test curves matched well. The analysis method of the double-nut ball screw was found to be concise and accurate, and the stiffness curves calculated using the two methods were consistent. The simulation analysis of the static stiffness presented herein is expected to aid the design of double-nut ball screws of high-rigidity heavy-duty equipment.
\end{abstract}

\section{Introduction}

A ball screw is widely used in mechanical equipment, particularly along the feed axis of CNC machine tools. The ball screw is characterized by high precision, high rigidity, micro feed, and high-speed feed [1]. However, the clearance between the ball and the roller induces an error in the ball screw. To solve this problem, double-nut ball screws have been developed. The pretightening method of a double-nut ball screw mainly includes positioning pretightening and fixed-pressure pretightening. Currently, the most common application of positioning pretension involves adding a rigid washer between the two nuts to generate an axial relative offset between them, thus generating an axial thrust. The pretension force can be controlled using gaskets of different thicknesses. The constant-pressure preload mainly produces an axial elastic tension force because of the spring installed between the two nuts. This is the axial preload force of the ball screw pair and is approximated to be a constant [2]. In this study, the positioning pretightening method was used.

The axial stiffness is the most important performance index of a ball screw. It significantly influences its positioning accuracy, dynamic performance, and transmission performance [3].

To design an optimized preload system for a ball screw, Verl et al. [4] studied the influences of preload force and nut and geometric parameters of the screw raceway on the axial stiffness of the ball screw from the nut structure. They 
proposed a calculation method for the axial stiffness of the ball screw. A geometrical error in the ball screw significantly affects its rigidity. Drossel et al. [5] presented an approach to reset the preload loss in ball screw drives, thus compensating for the loss of positioning accuracy due to wear over lifetime, and designed a novel shape memory alloy (SMA) bulk actuator module for ball screw drives.

Because of the complexity of the ball screw structure, it is difficult to establish its stiffness model, and many scholars have proposed different modeling methods. To study the influence of heat on the stiffness of a ball screw, Shi et al. [6] proposed a theoretical modeling method for the thermal error using fuzzy clustering and linear regression. Li et al. [7] combined the Monte Carlo method with a finite element method and proposed an adaptive real-time model.

This paper introduces a new method for calculating the static stiffness of a double-nut ball screw. Considering the geometric dimensions and material characteristics of doublenut ball screws and the analysis of the internal load distribution based on the Hertzian contact theory, a deformation model of the ball screw under load was established. Moreover, an axial stiffness model of the ball screw was established by analyzing the load acting on the ball screw. The stiffness model was applied to THK double-nut ball screws used in the $\mathrm{X}$-axis feed system of a high-stiffness heavy-duty friction stir welding robot developed by the research group. A finite element simulation was then conducted. The results showed that the static stiffness analysis method is accurate and effective and that the static stiffness curve obtained for a case study is in good agreement with the simulated curve. This study is expected to provide guidance and reference for the selection and design of transmission systems (ball screws) of high-rigidity heavy-duty equipment.

\section{Analysis and Calculation of Static Stiffness of Double-Nut Ball Screws}

The static stiffness of a ball screw refers to the axial stiffness along the ball screw. According to the calculation formula, the axial stiffness of a ball screw is the differential of the axial load it bears with respect to the change in the axial displacement [8]. Under the action of an axial working load, the relative displacement between the lead screws changes because of elastic deformation. However, this change is mainly due to the contact between the ball and the raceway induced by the change in the contact angle; the corresponding load acting on the ball bearings is also the normal load along the contact point. Therefore, to determine the axial contact stiffness of a ball screw, the relationship between the axial external load and the normal load acting on the ball screw must be obtained first. The relationship between the normal contact elastic deformation and the axial displacement of the ball screw can then be determined [9].

2.1. Geometric Parameters of Double-Nut Ball Screws. Figure 1 shows the geometric parameters of a double-nut ball screw.

The ball screw consists of a lead screw, screw nuts, and balls. Between the two screw nuts, the magnitude of the prestressing force can be adjusted using a prestressing gasket [10]. Nut A has a flange for easy mounting between the nut seats. Its external frame size parameters mainly include the nominal diameter, flange diameter, nut diameter, flange thickness, and pretightening gasket thickness of the screw. These geometric parameters are a part of the input conditions for stiffness calculation. The size parameters related to the ball and raceway inside the ball screw are also used in calculating the axial contact stiffness of the ball screw. The geometric parameters mainly include the contact angle, compactness, the numbers of columns and turns of the ball, the number of working balls, and the main curvature of each contact point between the ball and the raceway.

2.1.1. Helix Angle and Pitch. The section where nut A contacts the screw is taken as an example, as shown in Figure 2. The contact part between the ball and the screw side is represented by $i$, and the contact part between the ball and the nut side is represented by $e$. The pitch of the ball screw is the distance along the screw axis between the centers of two adjacent balls in the normal profile of the spiral raceway, represented by $P_{h}$.

The screw angle of the screw is the sharp angle formed between the tangent line of the screw cylinder helix and the straight line of the cylinder through the tangent point, expressed as $\lambda$.

$$
\lambda=\arctan \frac{P_{h}}{\pi d_{0}},
$$

where $\lambda$ and $d_{0}$ are the screw angle and nominal diameter of the ball screw, respectively.

2.1.2. Contact Angle and Raceway Curvature Ratio. The contact angle of the ball screw is defined as follows. In the normal profile of the screw raceway of the ball screw, the ball is tangent to the inner and outer raceways, and the connection between the center of the ball and the tangent point and the angle perpendicular to the axis of the ball screw is called the contact angle $\beta$, as shown in Figure 3 .

The contact angle has a significant effect on the contact stiffness of the ball screw. The greater this value, the greater the axial bearing capacity of the joint, i.e., the greater the axial stiffness. In addition, the greater the contact angle, the greater the transmission efficiency of the ball screw and the longer the service life. However, an excessive contact angle is not recommended, because this will make the position where the ball and raceway come into contact steeper, thus affecting welding precision or causing fatigue damage to the ball screw joint [11].

In Figure 3, the radius of the ball is $r_{w}$, the radius of the raceway curvature of the screw is $r_{i}$, and the radius of the raceway curvature of the nut is $r_{e}$. The ratio of the radius of the ball in the ball screw to the radius of the raceway curvature is called the raceway curvature ratio of the joint of the ball screw $\tau$. The curvature ratio of the raceway is an important factor affecting the ball screw. The greater the value, the closer the contact between the ball screw and the screw nut, the lower the contact stress, the greater the bearing capacity of the ball screw joint, and the greater the contact stiffness. 


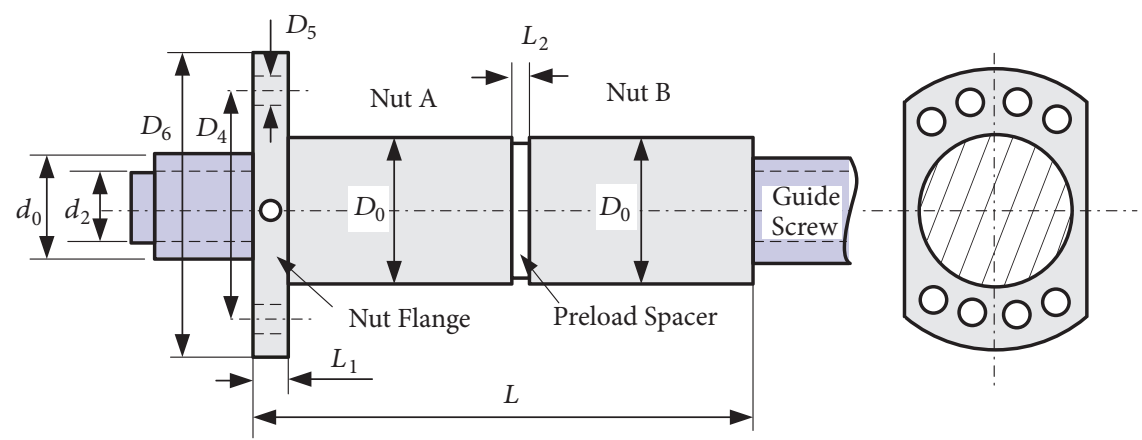

FiguRE 1: Geometric parameters of ball screw.

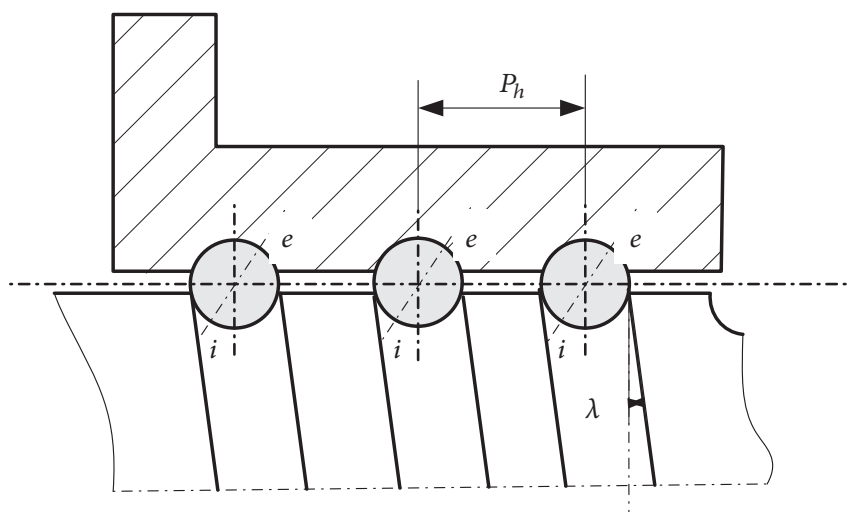

Figure 2: Schematic cross-sectional view of nut's A side.

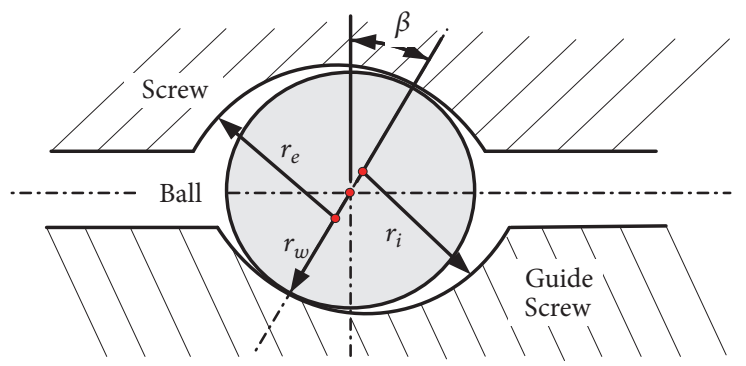

FIGURE 3: Contact between ball and raceway of ball screw.

On the contrary, the contact stiffness will decrease, and the contact stress will increase. For currently used ball screws, the raceway curvature ratio is generally 1.04 or 1.11 [12].

2.1.3. Number of Ball Columns, Rolls, and Working Balls. With reference to a multithread bolt, the number of columns of the ball bearings in a ball screw is the same as the number of threads or heads in the bolt. It refers to the number of ball chains that can operate independently around the screw. A screw with only one independent ball motion chain is called a single-row ball screw, one with two is called a double-row ball screw, and one with two or more ball chains is called a multirow ball screw. The winding number of ball bearings refers to the total number of windings of all working balls around the screw in the process of winding around the screw [13].
Generally, the load distribution of the working balls on the nut is uneven. The first round of the ball bearings can bear $30-40 \%$ of the total axial load, the second round approximately $20-30 \%$ of the total load, the third round only approximately $10-20 \%$ of the total load, and the back of the ball bearings only a small load or almost no load [14]. Therefore, generally, the number of cycles of the ball screw in a ball screw pair does not exceed three turns. The calculation formula for the number of working ball bearings in a single nut is as follows.

$$
z=i \frac{\pi d_{0}}{d_{w} \cos \lambda},
$$

where $z$ is the number of working ball bearings for a single nut, $i$ is the number of turns of the working ball in a single nut multiplied by the number of columns, and $d_{w}$ is the diameter of the ball. 
2.1.4. Principal Curvature and Sum of Principal Curvature between the Ball and Raceway. According to the Hertzian contact theory and the definition of principal curvature, the principal curvature at the contact point between the ball and the inner and outer raceways in the ball screw can be derived mathematically [15]. The main curvature between the ball and the inner and outer raceway is related to the nominal diameter, spiral angle, contact angle, and raceway curvature ratio of the ball screw. The four principal curvatures at the contact point $i$ between the ball and the screw raceway surface are as follows.

$$
\begin{aligned}
& \rho_{i 11}=\rho_{i 12}=\frac{2}{d_{w}} \\
& \rho_{i 21}=-\frac{2}{\tau d_{w}} \\
& \rho_{i 22}=\frac{2 \cos \beta \cos \lambda}{d_{0}-d_{w} \cos \beta}
\end{aligned}
$$

Similarly, the four principal curvatures at the contact point $e$ of the ball and the screw raceway surface are as follows:

$$
\begin{aligned}
& \rho_{e 11}=\rho_{e 12}=\frac{2}{d_{w}} \\
& \rho_{e 21}=-\frac{2}{\tau d_{w}} \\
& \rho_{e 22}=-\frac{2 \cos \beta \cos \lambda}{d_{0}+d_{w} \cos \beta}
\end{aligned}
$$

Therefore, with (3) and (4), the expressions of the sum of the principal curvature of the ball at the contact points $i$ and $e$ of the inner and outer raceways can be obtained.

$$
\begin{aligned}
& \sum \rho_{i}=\frac{4}{d_{w}}-\frac{2}{\tau d_{w}}+\frac{2 \cos \beta \cos \lambda}{d_{0}-d_{w} \cos \beta} \\
& \sum \rho_{e}=\frac{4}{d_{w}}-\frac{2}{\tau d_{w}}-\frac{2 \cos \beta \cos \lambda}{d_{0}+d_{w} \cos \beta}
\end{aligned}
$$

The above formula shows that the sum of the principal curvature of the contact point between the ball and the screw raceway surface should be greater than that between the ball and the screw raceway surface.

\subsection{Internal Load Distribution of Double-Nut Ball Screws.} Under the action of an external axial load, the ball screw transfers the load between the screw nuts through the balls between them, as shown in Figure 4(a). Assuming that the screw of the ball screw is subjected to an external axial force $F$, the normal force of the ball due to the extrusion between the screw and the screw is $F$, and all the balls are loaded equally [16].

Based on the spatial geometric relationship of each parameter in the figure, the relationship between the axial external load of the ball screw and the load in the ball direction can be obtained as follows.

$$
F=z Q \sin \beta \cos \lambda
$$

Figure 4(b) shows the elastic deformation of the ball under the action of normal load 1. It is assumed that the elastic deformation of the ball at the contact point $e$ with the screw raceway is $\delta_{e Q}$, and the elastic deformation at the contact point $i$ with the screw raceway is $\delta_{i Q}$. Therefore, under the action of axial workload $F$, the total elastic deformation of the ball screw due to normal force $Q$ is $\delta_{Q}$.

$$
\delta_{\mathrm{Q}}=\delta_{e \mathrm{Q}}+\delta_{i \mathrm{Q}}
$$

Based on the geometric relationship between the parameters, through the normal deformation $Q$ generated by the ball under the action of the normal force, the axial deformation $\delta_{a}$ generated between the screw nuts can be obtained as follows.

$$
\delta_{a}=\frac{\delta_{\mathrm{Q}} \cos \lambda}{\sin \beta}
$$

where $\delta_{a}$ is axial deformation of ball screw.

After determining the relationship between the axial force of the ball screw and the normal force of the ball and that between the axial deformation and the normal deformation of the ball, through the geometric parameters of the ball screw and Hertzian contact theory [17], the total normal contact deformation $\delta_{\mathrm{Q}}$ of the ball in the ball screw can be determined. The relationship between its axial contact deformation $\delta_{a}$ and the axial workload can be obtained from

$$
\begin{aligned}
\delta_{a} & =\left(\frac{\cos \lambda}{z^{2} \sin ^{5} \beta}\right)^{1 / 3}\left(\frac{2 K\left(e_{e \mathrm{Q}}\right)}{\pi m_{a e \mathrm{Q}}} \sqrt[3]{\frac{1}{8}\left(\frac{3}{E}\right) \sum \rho_{e \mathrm{Q}}}\right. \\
& \left.+\frac{2 K\left(e_{i \mathrm{Q}}\right)}{\pi m_{a i \mathrm{Q}}} \sqrt[3]{\frac{1}{8}\left(\frac{3}{E}\right) \sum \rho_{i \mathrm{Q}}}\right) F^{2 / 3}
\end{aligned}
$$

where $\sum \rho_{e Q}$ and $\sum \rho_{i \mathrm{Q}}$ are the sum of the principal curvature at the contact point of the ball with the screw and the screw raceway, respectively, $e_{e \mathrm{Q}}$ and $m_{a e \mathrm{Q}}$ are the coefficients associated with $\rho_{e Q}$ of the ball raceway point contact theory, $e_{i \mathrm{Q}}$ and $m_{a i \mathrm{Q}}$ are the coefficients associated with $\rho_{i \mathrm{Q}}$ of the ball raceway point contact theory, $K\left(e_{i \mathrm{Q}}\right)$ is the first type of complete elliptic integral related to elliptic eccentricities $e_{e}$ and $e_{i}$, and $E$ is the equivalent modulus of elasticity.

Equation (9) can be written as the product of a variable $K_{1}$ and the axial load borne by the ball screw, as follows.

$$
\delta_{a}=K_{1} F^{2 / 3}
$$

This is the relationship between the elastic deformation of the ball in contact with the raceway in the Hertzian contact theory and two-thirds of the external axial load [18]. And we can find that this variable is only related to the structural parameters of the ball screw itself and does not change with the change in the external load. The expression is as follows.

$$
\begin{aligned}
\delta_{a} & =\left(\frac{\cos \lambda}{z^{2} \sin ^{5} \beta}\right)^{1 / 3}\left(\frac{2 K\left(e_{e Q}\right)}{\pi m_{a e Q}} \sqrt[3]{\frac{1}{8}\left(\frac{3}{E}\right) \sum \rho_{e Q}}\right. \\
& +\frac{2 K\left(e_{i \mathrm{Q}}\right)}{\pi m_{a i \mathrm{Q}}} \sqrt[3]{\left.\frac{1}{8}\left(\frac{3}{E}\right) \sum \rho_{i \mathrm{Q}}\right)} F^{2 / 3}
\end{aligned}
$$




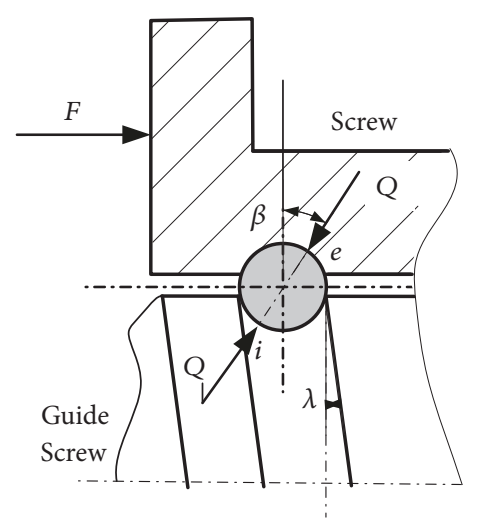

(a) Internal ball bearing condition

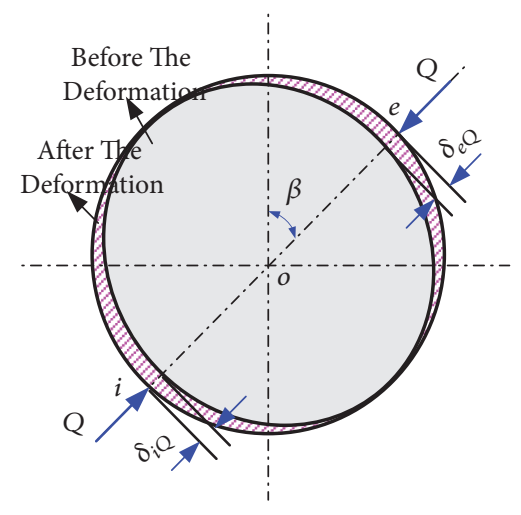

(b) Ball bearing deformation

FIgUre 4: Analysis of the load of ball screw.

2.3. Load Analysis of Double-Nut Ball Screws. The double nut pretightening ball screw is widely used in CNC machine tools. Compared with a single nut ball screw, there is no clearance between the screw and the mother screw in the transmission process, thus significantly improving the welding accuracy, and the presence of pretightening force also plays an important role in improving the axial contact stiffness of double-nut ball screws [19].

There are many types of pretightening structures for double nuts, and the positioning pretightening of a double nut is introduced here, as shown in Figure 5. Two screws are installed side by side on a ball screw, and the axial pretightening force is adjusted by adjusting the thickness of the pretightening gasket between the two screws. [20]. Here, nut A, which bears the working load, is the working nut, whereas nut $\mathrm{B}$, which does not bear the working load, is the pretightening nut. The advantages of this pretensioning method are simple structure, reliable pretensioning, convenient assembly and disassembly, and good axial rigidity.

It is noteworthy that the double nut pretensioning device cannot improve the axial bearing performance of the ball screw, but only enhance the axial stiffness of the joint and eliminate the transmission clearance. Moreover, in many applications, double-nut ball screws are operated with an exaggerated level of preloading most of the time, leading to excessive friction, wear, and heat generation.

Figure 6 shows the force analysis of the pretightening ball screw with double nuts. When the ball screw is not subjected to any external load, the right and left screws of the ball screw only bear the action of pretension force $F_{P}$ under the action of the intermediate pretension gasket. When screw nut $B$ on the right is subjected to axial workload $F$, the actual load on both sides of the acting screw nut changes to some extent. Because of the action of the working load, the actual load on nut A on the left side increases. The load on nut $A$ at this time is $F_{A}$ and the increased force is $F_{1}$. The bearing capacity of nut $\mathrm{B}$ on the right side decreases because of the action of the working load. Let its value be $F_{B}$ and the reduced load be $F_{2}$. Thus, nut B can be viewed as the pretightening nut and nut $A$ as the working nut. Under the above external load, the screw on both sides of the ball will bear the corresponding load. According to the assumption that the force acting on the ball is uniform, the normal contact force on the ball at the left nut $A$ is $Q_{A}$, and the normal contact force on the ball at the right nut $\mathrm{B}$ is $Q_{B}$.

Based on the load analysis of the pretightening ball screw with double nuts, the following expression can be obtained.

$$
\begin{aligned}
& F_{A}=F_{1}+F_{P} \\
& F_{B}=F_{P}-F_{2}
\end{aligned}
$$

Based on the relationship between the load of the screw and the normal force of the ball, (6) can be obtained.

$$
\begin{aligned}
Q_{A} & =\frac{F_{1}+F_{P}}{z \sin \beta \cos \lambda} \\
Q_{B} & =\frac{F_{P}-F_{2}}{z \sin \beta \cos \lambda}
\end{aligned}
$$

The above force analysis shows that nut $\mathrm{A}$, nut $\mathrm{B}$, and the pretightening gasket between them bear the external axial workload and the normal load of the ball acting along the groove. The force balance equation for the screw mother gasket assembly of a double-nut ball screw is as follows.

$$
F+Q_{B} z \sin \beta \cos \lambda=Q_{A} z \sin \beta \cos \lambda
$$

By substituting (13) into the above equation, the relation between the increments 1 and 2 of nuts $A$ and $B$ due to the external working load and axial load 3 can be obtained.

$$
F_{1}+F_{2}=F
$$

Based on the force analysis of the double-nut ball screw, as shown in Figure 4, the deformation of the ball screw under various types of loads can be obtained, as shown in Figure 7. $\delta_{P}$ is the elastic deformation of nuts $\mathrm{A}$ and $\mathrm{B}$ under the action of pretightening force $F_{P}$ of the pretightening gasket.

The red dotted lines in the figure indicate the deformed profiles of the nuts on both sides after the effect of pretension. $\delta_{a}$ and $\delta_{b}$ are the elastic deformations of nuts $\mathrm{A}$ and $\mathrm{B}$ on the left and right sides after the ball screw is subjected to the external axial load, respectively. The thin dotted lines in the 


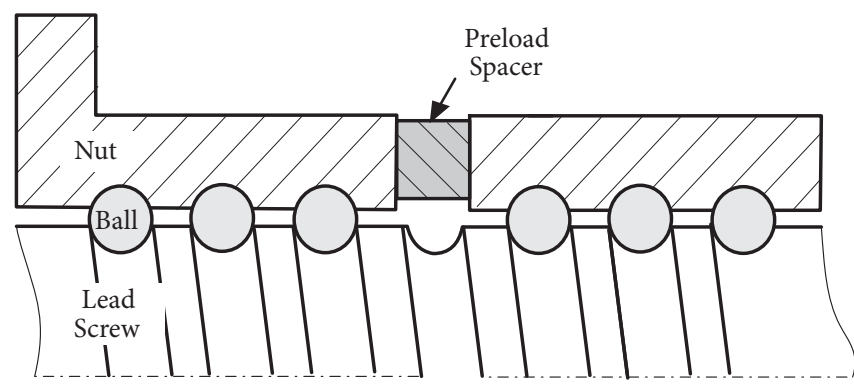

FIgURE 5: Gasket type with double-nut preloading.

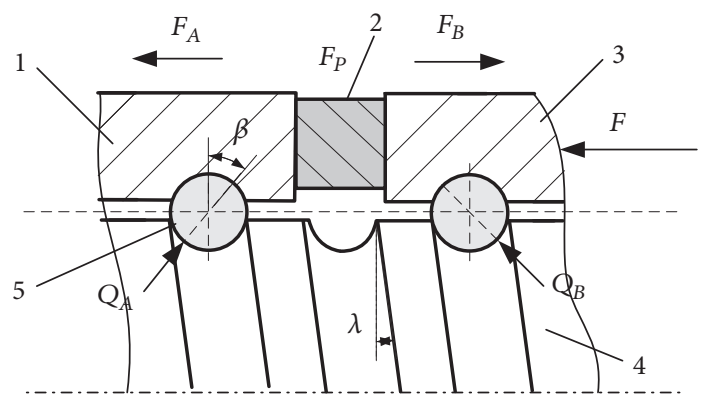

1 Nut A; 2 Preload spacer; 3 Nut B; 4 Screw; 5 Ball

FIGURE 6: Force analysis of ball screw in case of double-nut preloading.

figure indicate the elastic deformation of the nuts on both sides when the external axial load is further applied. Finally, the total elastic deformations of nuts $\mathrm{A}$ and $\mathrm{B}$ are $\delta_{A}$ and $\delta_{B}$, respectively.

$$
\begin{aligned}
& \delta_{A}=\delta_{a}+\delta_{P} \\
& \delta_{B}=\delta_{P}-\delta_{b}
\end{aligned}
$$

Based on the relationship between the axial force load acting on the ball screw and its axial deformation, the following relationships can be obtained by combining (10) and (16).

$$
\begin{aligned}
& \delta_{a}=K_{1}\left[\left(F_{P}+F_{1}\right)^{2 / 3}-F_{P}^{2 / 3}\right] \\
& \delta_{b}=K_{1}\left[F_{P}^{2 / 3}-\left(F_{P}-F_{2}\right)^{2 / 3}\right]
\end{aligned}
$$

After the ball screw pretightened by the double nuts is subjected to the external axial load, in addition to the compression deformation $\delta_{a}$ of nut $\mathrm{A}$ and the recovery deformation $\delta_{b}$ of nut $\mathrm{B}$, the pretightened gasket will also be compressed because of the pretightening force and external load, and its deformation is set to $\delta_{c}$ [21]. Based on material mechanics, the recovery deformation of a pretightening gasket can be expressed as follows.

$$
\delta_{c}=K_{c} F_{1}
$$

where $K_{c}$ is the stiffness of the pretensioned gasket and $K_{c}=$ $E A_{c} / l_{c}, E$ is the modulus of elasticity of the pretensioned gasket material, $l_{c}$ is the thickness of the pretensioned gasket, $A_{c}$ is the annular cross-sectional area of the pretensioned gasket material and $A_{c}=0.25 \pi\left(D_{2}{ }^{2}-D_{1}{ }^{2}\right), D_{2}$ is the outer diameter of the pretensioned gasket, and $D_{1}$ is the inner diameter of the pretensioned gasket.

According to the principle of equal deformation [22], the sum of the compression deformation of nut $\mathrm{A}$ and the compression deformation of the pretightening gasket is equal to the restoration deformation of nut $\mathrm{B}$. The deformation coordination equation is as follows.

$$
\delta_{a}+\delta_{c}=\delta_{b}
$$

Therefore, the following expressions can be obtained from (17) and (18):

$$
\begin{gathered}
K_{1}\left[\left(F_{P}+F_{1}\right)^{2 / 3}-F_{P}^{2 / 3}\right]+K_{c} F_{1} \\
=K_{1}\left[F_{P}^{2 / 3}-\left(F_{P}-F_{2}\right)^{2 / 3}\right]
\end{gathered}
$$

If the above equation is connected to (15), and if the external axial load $F$ of the pretightening ball screw with double nuts is known, the two nonlinear equations can be solved, and the values of $F_{1}$ and $F_{2}$ can be obtained. Finally, the axial contact stiffness of the pretightening ball screw can be obtained from the axial stiffness formula of the ball screw.

$$
K=\frac{d F}{d \delta_{\text {axis }}}
$$

where $K$ is the axial stiffness of the ball screws pretightened by double nuts and $\delta_{\text {axis }}$ is the axial contact deformation of the ball screw. 


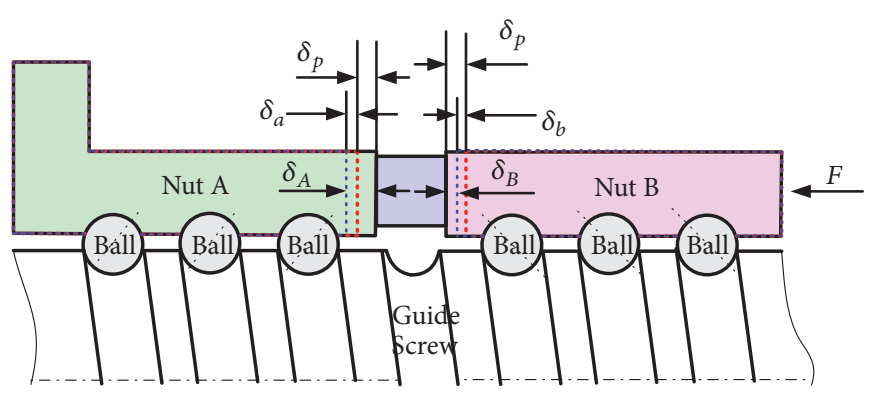

FIGURE 7: Deformation analysis of ball screw in case of double-nut preloading.

\section{Instance Analysis}

As an example, the $\mathrm{X}$-axis feed system of a high-stiffness heavy-duty friction stir welding robot developed by the research group was analyzed [23]. The ball screw (model number TDB-S-8010) of this system was manufactured by Spain Shuton Company. TD represents the double nuts with pretightening, B represents the flange nuts with edges, $\mathrm{S}$ represents the internal circulation of the ball, and 8010 indicates that the nominal diameter of the ball screw is $80 \mathrm{~mm}$ and that its lead is $10 \mathrm{~mm}$. Table 1 lists the detailed parameters.

During the operation of the friction stir welding robot, the pretightening force $F_{P}$ is $10000 \mathrm{~N}$ set by the $\mathrm{X}$-axis ball screw, and the variation range of the external axial load $F$ is 5000-40000 N. Table 1 lists the other structural parameters of the ball screw. The screw nut, lead screw, and balls are made of bearing steel, and its elastic modulus and Poisson's ratio can be obtained by looking up the material manual.

Through the above formula for calculating the stiffness of the double-nut ball screws under the action of pretightening force, the stiffness curve of the axial contact stiffness of the robot $\mathrm{X}$-axis TDB ball screw with respect to the external working load is plotted, as shown in Figure 8.

The figure shows that when the preset pretension force of the double-nut ball screw is $10000 \mathrm{~N}$, its axial stiffness increases with the increase in the external axial working load. When the axial working load is lower than $1.1 \times 10^{4}$ $\mathrm{N}$, its stiffness increases significantly with the increase in the working load; when the working load is greater than $1.1 \times 10^{4}$ $\mathrm{N}$, its rising slope tends to stabilize.

\section{Finite Element Simulation of Double-Nut Ball Screws}

To verify the accuracy of the theoretical calculation, a finite element analysis method was used to plot the stiffness curve of the ball screw. To facilitate the establishing of the threedimensional model of the ball screw, a ball screw model with half a ball was selected, as shown in Figure 9. To improve the calculation accuracy of nonlinear contact and reduce the calculation convergence time, the mesh at the contact point was refined by referring to the segmentation method used for angular contact ball bearings [24]. The surface contact units TARGE170 and CONTA174 were selected for the contact position of the ball and the inner and outer raceway, respectively, and the material properties of each component were given. Finally, the full finite element model of the ball screw is established by extending the above finite element model using mirror image and array.

After the ball screw is divided into hexagonal structured grids with SOLID45, the numbers of grids and nodes are 756865 and 421378, respectively. The screw nut, lead screw, and balls are made of bearing steel with an elastic modulus of 2.06E5 MPa and a Poisson's ratio of 0.3. As the entire ball screw only bears the external workload from the axial direction, the following boundary conditions were specified during the analysis [25]:

(1) The degrees of freedom of the end face of the screw are subjected to all fixed constraints.

(2) The end face of the screw nut allows the degrees of freedom along the axial direction and restrains the degrees of freedom in other directions.

(3) The internal ball bearings constrain the tangential degrees of freedom along the cylindrical coordinate system and allow the other two degrees of freedom.

In addition, the load condition needs to be specified for the ball screw, including the application of preload and axial working load. The pretightening force unit PRETS179 provided in ANSYS was used to simulate the effect of the pretightening gasket. The pretightening force can be set to 1.0 $\times 10^{4} \mathrm{~N}$ in the middle of the two nuts. An external axial load is applied to the end face of the pretightening nut, and ANSYS analysis and calculation are then performed. Figure 10 shows the finite element analysis results of the double-nut ball screws under preload $F_{P}=1.0 \times 10^{4} \mathrm{~N}$ and external axial load $F=2.5 \times 10^{4} \mathrm{~N}$. Following are the conclusions drawn from the figure:

(1) Because of the effects of pretightening force and external load, the displacement directions of nut $\mathrm{A}$ side and nut $B$ side are opposite, and the absolute value of the ball displacement near the gasket is relatively high.

(2) As shown in Figure 10(b), the contact stress of the ball inside the working nut $A$ is greater than that of the pretightening nut $\mathrm{B}$. The closer it is to the pretightening washer, the greater the stress value is.

(3) The maximum axial displacement of nut $\mathrm{A}$ is $0.208 \mathrm{e}-$ $2 \mathrm{~mm}$, the maximum von Mises stress of the ball is $140 \mathrm{MPa}$, and the ball stress on each side decreases successively.

Finally, the axial contact stiffness of the ball screw can be obtained by dividing the axial workload by the maximum 
TABLE 1: Geometric parameters of TDB-S-8010-type ball screw.

\begin{tabular}{lcc}
\hline Parameter & Symbols and units & Number \\
\hline Nominal diameter & $d_{0}(\mathrm{~mm})$ & 80 \\
Helical pitch & $P_{h}(\mathrm{~mm})$ & 10 \\
Nut outer diameter & $D_{0}(\mathrm{~mm})$ & 105 \\
The ball diameter & $D_{w}(\mathrm{~mm})$ & $\beta .35$ \\
Contact angle & $\beta\left(^{\circ}\right)$ & $\lambda\left(^{\circ}\right)$ \\
Helical angle & $3 \tau$ & 30 \\
Raceway curvature ratio & $i$ & 1.04 \\
Number of columns times the number of rolls & $L_{2}(\mathrm{~mm})$ & 6 \\
Thickness of pre-tightening gasket & $D_{2}(\mathrm{~mm})$ & 14 \\
Outer diameter of pre-tightening gasket & $D_{1}(\mathrm{~mm})$ & 100 \\
Pre-tightening gasket inner diameter & $L_{1}(\mathrm{~mm})$ & 20 \\
The thickness of the flange & $L(\mathrm{~mm})$ & 290 \\
Total nut length & & 20 \\
\hline
\end{tabular}

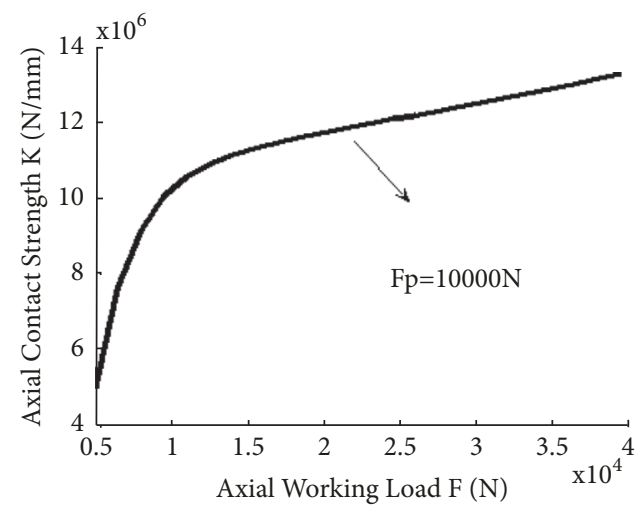

FIGURE 8: The stiffness curve of ball screw changes when the pretightening force is $10000 \mathrm{~N}$.

displacement in this direction. To compare the finite element analysis data with the theoretical results of stiffness, the axial working load was taken in the range of $0.5 \times 10^{4}-4.0 \times 10^{4} \mathrm{~N}(\mathrm{a}$ total of eight groups of data), and the calculated results were converted into stiffness data. Figure 11 shows the stiffness curve of the double-nut ball screw under external loading.

The figure shows that when the external axial load is lower than $2.4 \times 10^{4} \mathrm{~N}$, the axial stiffness of the double-nut ball screw obtained using the finite element method is lower than the theoretical value, mainly because the finite element model takes into account the flexibility of the structure and changes in the ball contact angle and other factors. In addition, the grid precision of the contact area significantly affects the accuracy of the results; however, to save computing resources and time, the grid cannot be divided too finely. When the external axial load is greater than $2.4 \times 10^{4} \mathrm{~N}$, with further increase in the external load, the axial stiffness calculated using the finite element method becomes gradually closer to the theoretical value. This shows that when the external load is relatively high, the finite element calculation results are close to the theoretical calculation results. In particular, when the axial load reaches $3.0 \times 10^{4} \mathrm{~N}$, the simulated and test curves are in good agreement. Therefore, when the joint stiffness of the friction stir welding robot is selected, it can be considered comprehensively according to the load.

The two curves (Figure 11) show that when the external load is in the range of $0.5 \times 10^{4}-2.4 \times 10^{4} \mathrm{~N}$, the theoretical value is greater than the simulated one, mainly because the structural flexibility and changes in the ball contact angle and friction coefficient were considered in the finite element model.

\section{Conclusions}

This study proposes a simple, accurate, and feasible method for calculating the static stiffness of a double-nut ball screw. After analyzing the structure and internal load distribution of the ball screw, a load-bearing deformation model was established based on the Hertzian contact theory. Through the load-bearing analysis of the ball screw, a static stiffness model of the ball screw was established. The model was applied to a case study and a finite element simulation. The rigidity of THK double-nut ball screws used in the X-axis feed system of a high-stiffness heavy-duty friction stir welding robot (developed by the research group) was calculated. When the axial working load was lower than $1.1 \times 10^{4} \mathrm{~N}$, the axial static stiffness of the double nuts increases significantly 


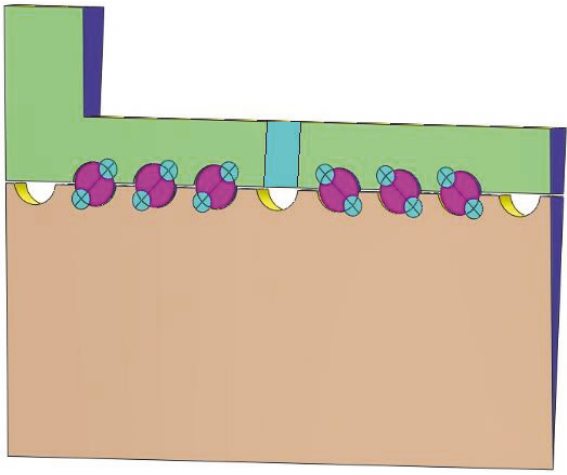

(a) Geometric model of half ball screw pair

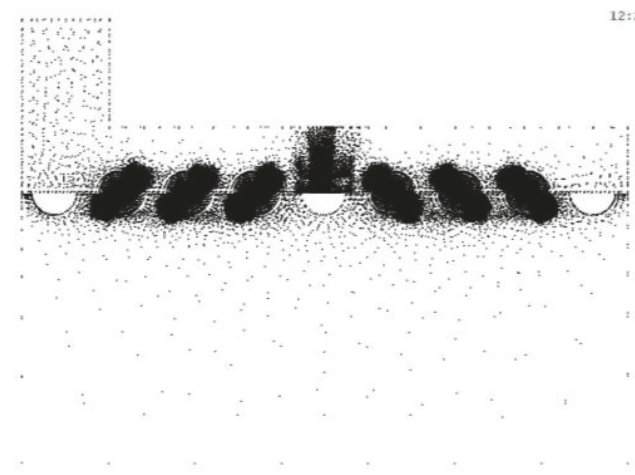

(b) Fine grid division of ball raceway contact area

FIGURE 9: Finite element model of double-nut ball screw.

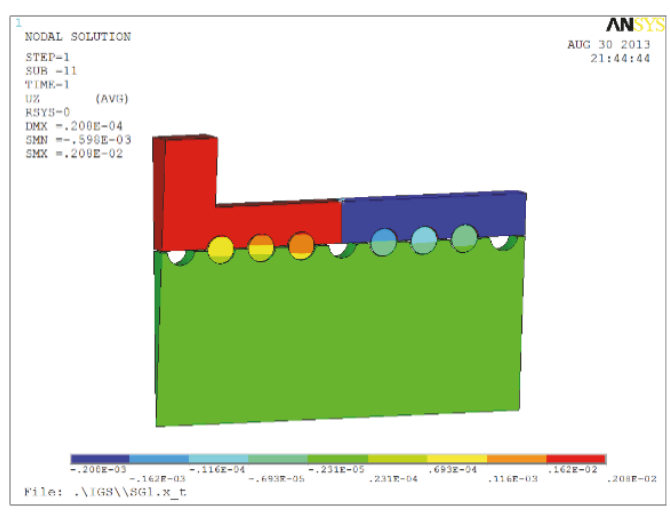

(a) Axial displacement

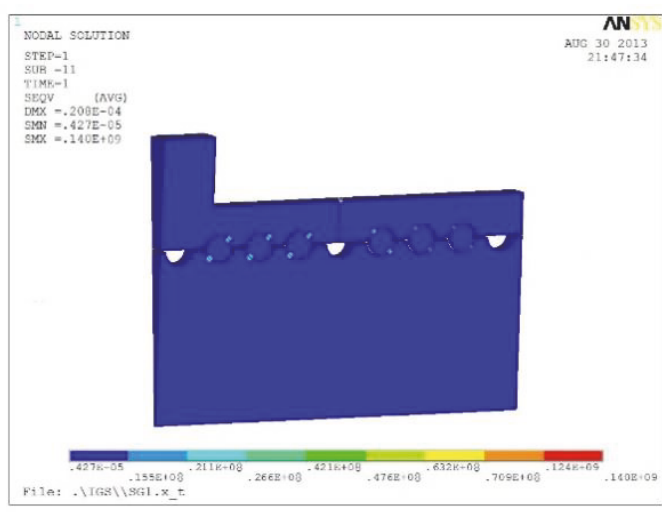

(b) Von Mises stress

FIGURE 10: Results of finite element analysis of double-nut ball screws.

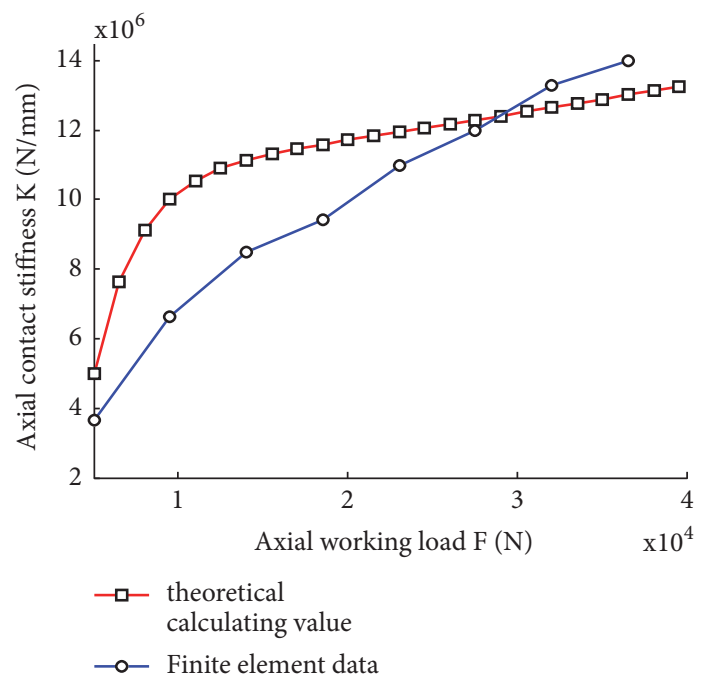

FIgURE 11: Axial contact stiffness contrast of double-nut ball screws. 
with the increase in the working load. When the working load was greater than $1.1 \times 10^{4} \mathrm{~N}$, the rising slope tends to stabilize. The stiffness curves obtained from the simulation and experimental results were in good agreement. When the external axial load was greater than $2.8 \times 10^{4} \mathrm{~N}$, the stiffness calculated using the finite element method gradually tends to the theoretical value. When the axial load was $3.0 \times 10^{4} \mathrm{~N}$, the two curves were in good agreement.

Under the $\mathrm{X}$-axis working condition of the robot, when the external load was in the range of $0.5 \times 10^{4}-2.4 \times 10^{4}$ $\mathrm{N}$, the theoretical stiffness value differed significantly from the simulated value, mainly because the structural flexibility and changes in the ball contact angle and other factors were considered in the finite element model. In addition, in order to save computing resources and time, the grid accuracy of the contact area is low, which also has a great impact on the accuracy of the results. Future studies will involve considering the flexibility of the structure and the variation in ball contact angle and other factors when establishing the stiffness model and improving the mesh precision of the contact area when the finite element model is established.

\section{Data Availability}

No data were used to support this study.

\section{Conflicts of Interest}

The authors declare no potential conflicts of interest with respect to the research, authorship, and/or publication of this article.

\section{Acknowledgments}

This research was supported by the National Natural Science Foundation of China (grant number 51505470); State Key Laboratory of Robotics; Youth Innovation Promotion Association, CAS (2018237); and Jiang Xinsong Innovation Fund.

\section{References}

[1] N. Zhen and Q. An, "Analysis of stress and fatigue life of ball screw with considering the dimension errors of balls," International Journal of Mechanical Sciences, vol. 137, pp. 68-76, 2018.

[2] A. Oyanguren, P. Zahn, A. H. Alberdi, J. Larrañaga, A. Lechler, and I. Ulacia, "Preload variation due to temperature increase in double nut ball screws," Production Engineering Research and Development, vol. 10, no. 4-5, pp. 529-537, 2016.

[3] B. M. Iznairov, A. V. Korolev, and A. A. Korolev, "Improving the assembly of ballscrews using analysis of interactions between the working parts," Procedia Engineering, vol. 150, pp. 502-505, 2016.

[4] A. Verl, S. Frey, and T. Heinze, "Double nut ball screw with improved operating characteristics," CIRP Annals - Manufacturing Technology, vol. 63, no. 1, pp. 361-364, 2014.

[5] W. Drossel, T. Junker, A. Bucht, I. N. y de Sosa, and K. Pagel, "Evaluation of shape memory alloy bulk actuators for wear compensation in ball screw drives," IFAC-PapersOnLine, vol. 49, no. 21, pp. 88-94, 2016.

[6] H. Shi, D. Zhang, J. Yang, C. Ma, X. Mei, and G. Gong, "Experiment-based thermal error modeling method for dual ball screw feed system of precision machine tool," The International Journal of Advanced Manufacturing Technology, vol. 82, no. 9-12, pp. 1693-1705, 2016.

[7] T.-J. Li, C.-Y. Zhao, and Y.-M. Zhang, "Adaptive real-time model on thermal error of ball screw feed drive systems of CNC machine tools," The International Journal of Advanced Manufacturing Technology, vol. 94, no. 9-12, pp. 3853-3861, 2018.

[8] T. Miura, A. Matsubara, D. Kono, K. Otaka, and K. Hoshide, "Design of high-precision ball screw based on small-ball concept," Precision Engineering, vol. 47, pp. 452-458, 2017.

[9] N. A. Rafan, Z. Jamaludin, T. H. Chiew, L. Abdullah, and M. N. Maslan, "Contour error analysis of precise positioning for ball screw driven stage using friction model feedforward," Procedia CIRP, vol. 26, pp. 712-717, 2015.

[10] J. Fleischer, A. Spohrer, U. Leberle, and S. Dosch, "Adaptive and adequate lubrication for highest component-lifetimes in feed drive axes with ball screws," in Procedia CIRP, pp. 335-340, Northeastern University, Shenyang, China, 2015.

[11] A. Amanov and Y. S. Pyun, "Lowering friction of ball screws made of different steel grades through ultrasonic impact treatment," Tribology International, vol. 123, pp. 105-119, 2018.

[12] H. Zhou, The Mode Analysis of Ball Screw Pair And Its Motion Reliability Analysis [M. S. thesis], Northeastern University, Shenyang, China, 2011.

[13] Y. Liu, L. Xu, and L. Zuo, "Design, modeling, lab, and field tests of a mechanical-motion-rectifier-based energy harvester using a ball-screw mechanism," IEEE/ASME Transactions on Mechatronics, vol. 22, no. 5, pp. 1933-1943, 2017.

[14] W. He, Principle and Application of CNC Machine Tool, China Machine Press, Beijing, China, 2007.

[15] A. Oyanguren, J. Larrañaga, and I. Ulacia, “Thermo-mechanical modelling of ball screw preload force variation in different working conditions," The International Journal of Advanced Manufacturing Technology, vol. 97, no. 1-4, pp. 723-739, 2018.

[16] C. Zhang and Y. Chen, "Tracking control of ball screw drives using adrc and equivalent-error-model-based feedforward control," IEEE Transactions on Industrial Electronics, vol. 63, no. 12, pp. 7682-7692, 2016.

[17] A. Zhu, S. He, J. Zhao, and W. Luo, "A nonlinear contact pressure distribution model for wear calculation of planar revolute joint with clearance," Nonlinear Dynamics, vol. 88, no. 1, pp. 315-328, 2017.

[18] J. Zhang, H. Zhang, C. Du, and W. Zhao, "Research on the dynamics of ball screw feed system with high acceleration," The International Journal of Machine Tools and Manufacture, vol. 111, pp. 9-16, 2016.

[19] T. Liang, D. Lu, X. Yang, J. Zhang, X. Ma, and W. Zhao, "Feed fluctuation of ball screw feed systems and its effects on part surface quality," The International Journal of Machine Tools and Manufacture, vol. 101, pp. 1-9, 2016.

[20] T. Benhaddou, P. Stephan, A. Daidie, F. Alkatan, C. Chirol, and J. Tuery, "Effect of axial preload on durability of aerospace fastened joints," International Journal of Mechanical Sciences, vol. 137, pp. 214-223, 2018.

[21] Z. Du, X. L. Zhang, and T. Tao, "Study of the dynamic characteristics of ball screw with a load disturbance," in Mathematical Problems in Engineering, 2016. 
[22] K. Khorshidi and A. Fallah, "Buckling analysis of functionally graded rectangular nano-plate based on nonlocal exponential shear deformation theory," International Journal of Mechanical Sciences, vol. 113, pp. 94-104, 2016.

[23] M. H. Wan, W. J. Zhou, H. T. Luo, and Y. Z. Tian, "Design and motion control of the high precision heavy load friction stir welding robot," Robot, vol. 40, no. 6, pp. 817-824, 2018.

[24] H. Cui, Y. Wang, H. Yang et al., "Numerical analysis and experimental research on the angular stiffness of aerostatic bearings," Tribology International, vol. 120, pp. 166-178, 2018.

[25] X. Chen and Y. Huang, "Nanomechanics modeling and simulation of carbon nanotubes," Journal of Engineering Mechanics, vol. 134, no. 3, pp. 211-216, 2008. 


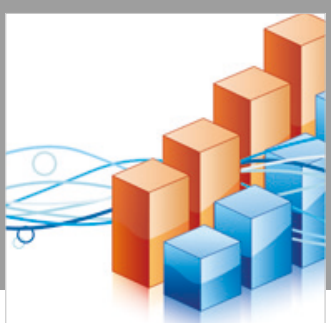

Advances in

Operations Research

\section{-n-m}
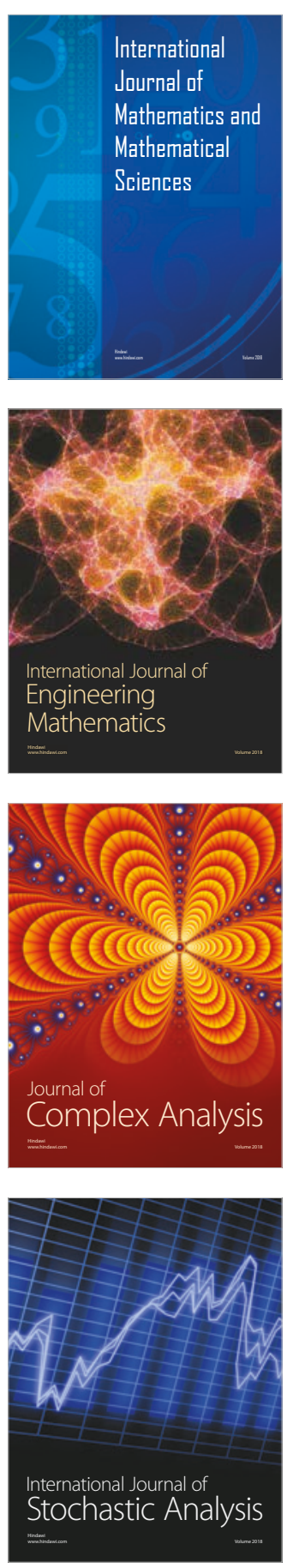
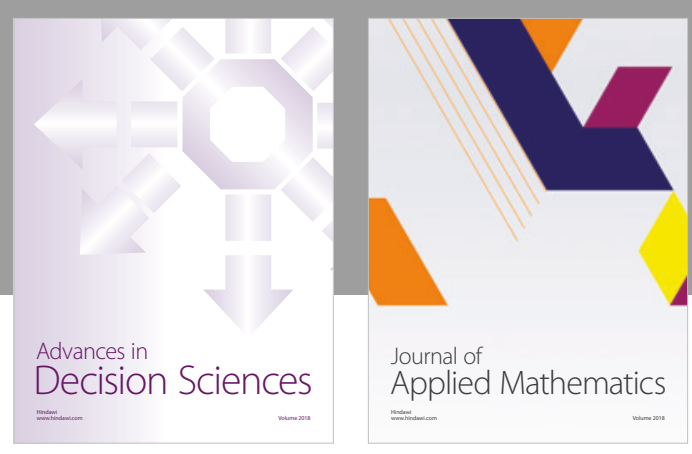

Journal of

Applied Mathematics
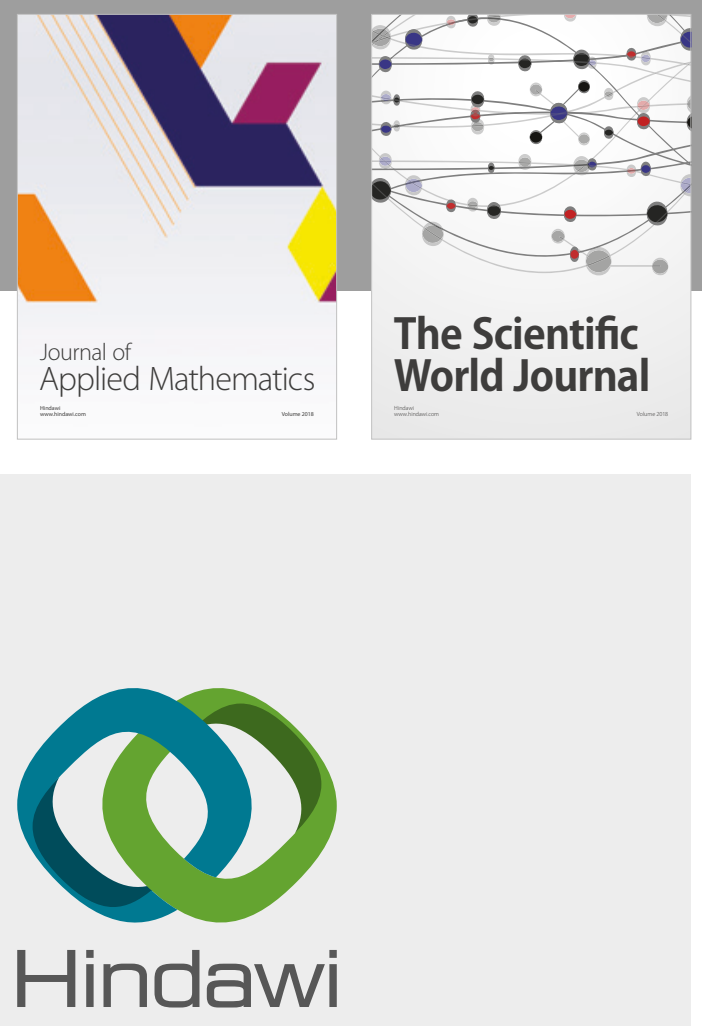

Submit your manuscripts at

www.hindawi.com

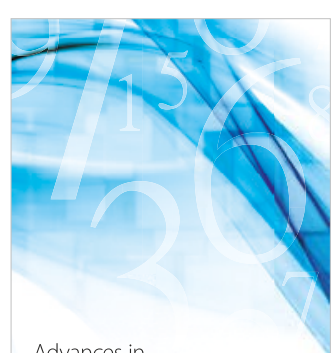

Advances in
Numerical Analysis
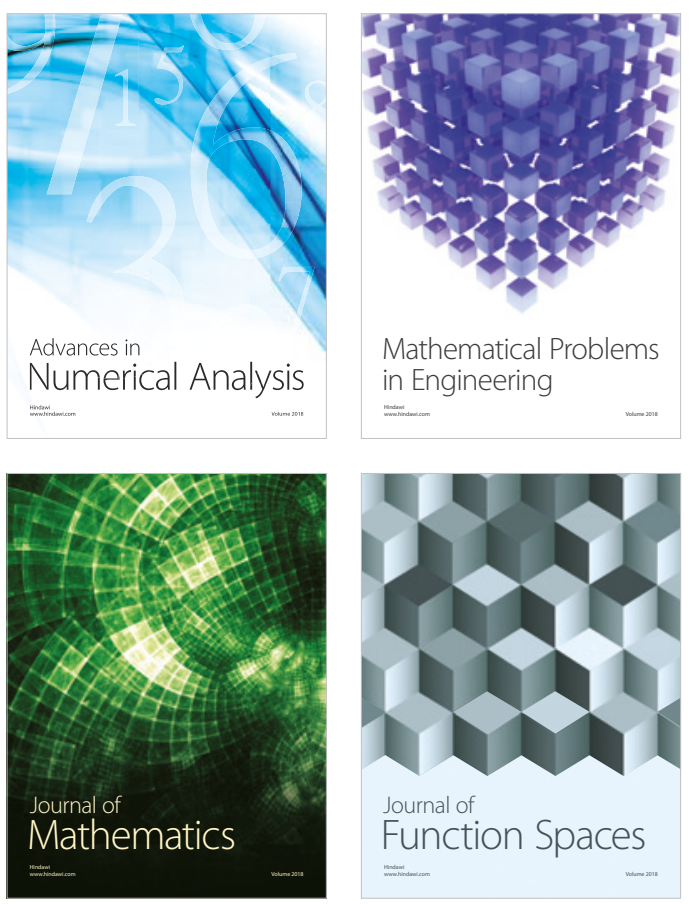

Mathematical Problems in Engineering

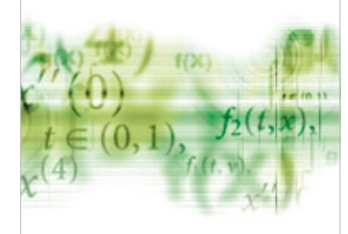

International Journal of

Differential Equations

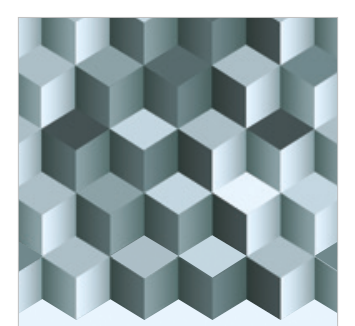

Journal of

Function Spaces
The Scientific

World Journal

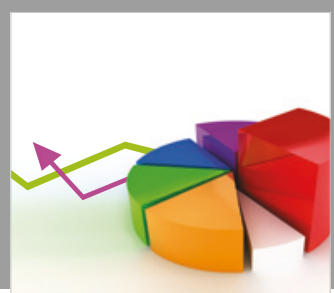

Journal of

Probability and Statistics
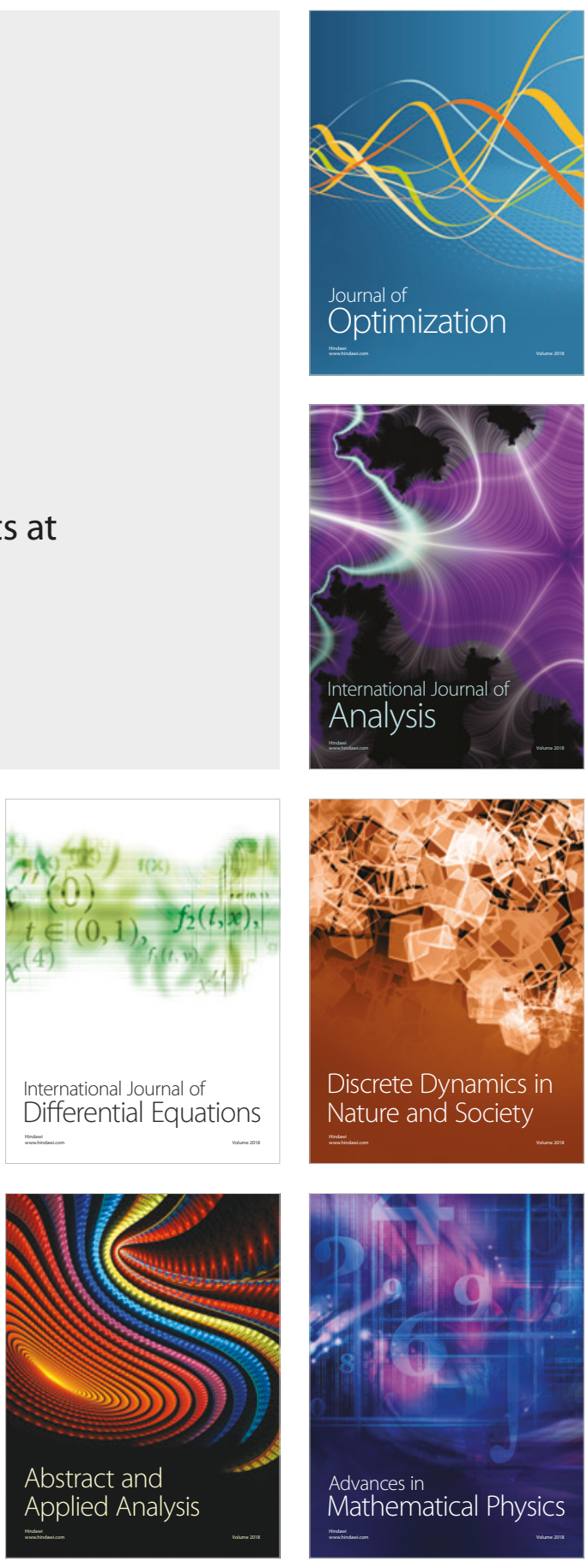